Results Total numbers of patients receiving NIV decreased by $45.8 \%$ from 2019 to 2020 (83 vs 45 patients) with a $37.7 \%$ drop in number of COPD patients (53 vs 33). The Median (Interquartile range (IQR) time from decisive ABG to NIV setup was 61 mins (34) in 2019, which increased to 132 mins (113) in $2020(\mathrm{P}<0.0001)$. Notably, the proportion of patients meeting the BTS target decreased from $48.7 \%$ to $23.7 \%$ $(\mathrm{P}<0.0001)$. The number of critical care set ups decreased from 9 to $1 \quad(\mathrm{P}=0.0232)$. Moreover, the proportion of patients who completed NIV decreased by $68.8 \%$ (48 vs 15 ) $(\mathrm{P}=0.0081)$, with number of deaths increasing by $50 \%$ (4 vs 8) $(\mathrm{P}=0.0136)$.

Conclusions The reduction in patient numbers receiving NIV for acidotic respiratory failure is likely due to a decrease in acute COPD exacerbations. However, NIV set up times significantly increased, reflecting the stringent COVID-19 infection control measures around aerosol generating procedures. We report a decrease in critical care set ups and an increase in deaths in 2020, highlighting excess deaths in patients receiving NIV subsequently found to be due to COVID-19. Given ongoing infection controls, global restructuring and improvement of patient flow through hospitals may be required as part of future quality improvement for decreasing response times for acute NIV set-ups.

\section{P16 EFFECT OF HUMIDIFIER TEMPERATURE DURING HIGH FLOW NASAL THERAPY ON CONCURRENT AEROSOL DRUG DELIVERY WITH A VIBRATING MESH NEBULISER}

B Murphy, O O'Sullivan, G Bennett, E Fernandez Fernandez, R MacLoughlin. Aerogen Ltd., Galway, Ireland

10.1136/thorax-2021-BTSabstracts. 126

High flow nasal therapy (HFNT) is commonly used to treat patients that require supplemental oxygen and prescribed lung targeted aerosol drug delivery. Humidifier temperature may impact the percentage of drug dose delivered to patients. This study investigates the effects of humidifier temperature, $34^{\circ} \mathrm{C} v 37^{\circ} \mathrm{C}$, during $\mathrm{HFNT}$ on the performance of a vibrating mesh nebuliser (VMN) (Aerogen Solo, Aerogen, Ireland).

A $2.5 \mathrm{ml}$ dose of $2 \mathrm{mg} / \mathrm{ml}$ of salbutamol was nebulised using a VMN with the Airvo2 HFNT system via the nebuliser adapter (Fisher \& Paykel, New Zealand). A capture filter was placed distal to the nasal prongs of an adult nasal cannula (OPT944) and emitted dose characterised at 10, 30 and 60 LPM. Drug dose was determined by quantifying the mass of drug captured on the filters using UV spectrophotometry at $276 \mathrm{~nm}$.

Abstract P16 Table 1 Emitted dose (\%) for VMN in combination with the Airvo2 at $34^{\circ} \mathrm{C}$ and $37^{\circ} \mathrm{C}$

Emitted Dose (\%) (Average \pm SD)

\begin{tabular}{lccc}
\hline Flow rate & Temperature $34^{\circ} \mathrm{C}$ & Temperature $37^{\circ} \mathrm{C}$ & P-Value \\
\hline 10 LPM & $33.79 \pm 1.72 \%$ & $33.34 \pm 2.42 \%$ & 0.810 \\
30 LPM & $30.25 \pm 2.98 \%$ & $28.50 \pm 0.70 \%$ & 0.430 \\
60 LPM & $19.17 \pm 1.15 \%$ & $18.88 \pm 0.52 \%$ & 0.732 \\
\hline
\end{tabular}

Results of this work indicate that the humidifier temperature setting has no significant effect on the emitted aerosol drug dose across flow rates. Consequently, the clinician has the option to adjust temperature without concerns around altered aerosol dosing.

\section{P17 CHARACTERISTICS AND OUTCOMES OF PATIENTS WITH SPINAL CORD INJURY REQUIRING MECHANICAL VENTILATION AT A SPECIALIST VENTILATION CENTRE, 2010-2019}

SK Shrimanker, NM Shah, M Freeman, RF D'Cruz, G Kaltsakas, P Marino, H Pattani, MC Ramsay, S Srivastava, J Steier, N Hart, PB Murphy, ES Suh. Guy's and St Thomas' Hospital Trust, London, UK

\subsection{6/thorax-2021-BTSabstracts. 127}

Introduction Patients with spinal cord injury (SCI) often require complex ventilatory management but limited data exist on this cohort of patients. We sought to characterise the cohort of SCI patients who have received mechanical ventilation at our tertiary ventilation centre.

Methods A retrospective database evaluation of all patients referred to our centre between 2010 and 2019 with SCI and respiratory failure.

Results 205 adults (65\% male) were evaluated. Median(IQR) age at time of injury was 43(24-66) years. $84 \%$ suffered a high cord injury (C1-C5) and 16\% suffered a lower cord injury (C6 and below). Patients suffered from ASIA Grade A (70\%), Grade B (16\%), Grade C (10\%) and Grade D (4\%) injuries. $8 \%$ patients were successfully weaned from all mechanical ventilation prior to discharge. $87 \%$ of patients were established on long-term home mechanical ventilation: $50 \%$ with IMV, $37 \%$ with NIV. $4 \%$ of patients died prior to hospital discharge. $74 \%$ of patients were discharged with mechanical insufflation-exsufflation therapy. Regarding discharge destination, $67 \%$ were discharged to their home however, due to high multi-disciplinary care needs, $7 \%$ were discharged to a rehabilitation hospital and $25 \%$ were discharged to a nursing home. Time to death following injury was 5(2-19) years, with age at death of 67(56-73) years. Time to death following injury was 22(3-26) years in the NIV cohort and $7(2-12)$ years in the IMV cohort. Patients remained under specialist follow-up from our unit for $4(2-7)$ years.

Conclusion The majority of patients referred with respiratory failure following SCI who survive to discharge are successfully established on long-term ventilatory support. One quarter require care in long-term residential facilities. Three-quarters are provided with mechanical insufflation-exsufflation therapy to aid secretion clearance. Median survival is considerably longer in SCI patients than other groups requiring long-term mechanical ventilation, ${ }^{1}$ indicating a need for long-term management strategies to maximise functional capacity and improve health-related quality of life in this patient population.

\section{REFERENCE}

1. Patout $M$, Lhuillier $E$, Kaltsakas $G$, et al. Long-term survival following initiation of home non-invasive ventilation: a European study. Thorax 2020;75:965-973. 